NASA Technical Memorandum 101358

\title{
Stochastic Modeling of Crack Initiation and Short-Crack Growth Under Creep and Creep-Fatigue Conditions
}

Takayuki Kitamura

Lewis Research Center

Cleveland, Ohio

Louis J. Ghosn

Cleveland State University

Cleveland, Ohio

and

Ryuichi Ohtani

Kyoto University

Kyoto, Japan

(HASA-TH-101358) STOCEASTIC ECEELIHG OF

CEACK IAITIATICE IND SECET-CEACK GECHT H

OALER CEEEE AUC CEEEP-FATIGOE CCADITIONS

(NASA) $20 \mathrm{~F}$

CSCL $20 \mathrm{~K}$

N89-17286

January 1989 


\title{
STOCHASTIC MODELING OF CRACK INITIATION AND SHORT-CRACK GROWTH \\ UNDER CREEP AND CREEP-FATIGUE CONDITIONS
}

\author{
Takayuki Kitamura* \\ National Aeronautics and Space Administration \\ Lewis Research Center \\ Cleveland, Ohio 44135 \\ Louis J. Ghosn** \\ Cleveland State University \\ Cleveland, Ohio 44115
}

and

Ryuichi Ohtani

Kyoto University

Kyoto, Japan

\section{SUMMARY}

A simplified stochastic model is proposed for crack initiation and short-crack growth under creep and creep-fatigue conditions. Material inhomogeneity provides the random nature of crack initiation and early growth. In the model, the influence of microstructure is introduced by the variability of (1) damage accumulation along grain boundaries, (2) critical damage required for crack initiation or growth, and (3) the grain-boundary length. The probabilities of crack initiation and growth are derived by using convolution integrals. The model is calibrated and used to predict the crack density and crack-growth rate of short cracks of 304 stainless steel under creep and creepfatigue conditions. The mean-crack initiation lives are predicted to be within an average deviation of about 10 percent from the experimental results. The predicted cumulative distributions of crack-growth rate follow the experimental data closely. The applicability of the simplified stochastic model is discussed and the future research direction is outlined.

\section{INTRODUCTION}

Life prediction is an important parameter in evaluating the safety and reliability of structural components for high-temperature applications such as rocket engines, gas turbines, and nuclear powerplants. Crack initiation and early growth constitute most of the life of components, especially under creep and creep-fatigue conditions. Experimental observations (Ohtani et al., 1983, 1986, 1987) have shown large fluctuations in the crack initiations and growth

\footnotetext{
*National Research Council - NASA Research Associate, on leave from the Department of Engineering Science, Kyoto University, Kyoto, Japan.

**NASA Resident Research Associate.
} 
rates of short cracks. These fluctuations are caused by the randomness in the grain size, the local stress, and the resistance to local fillure. Few analyses have been conducted of the stochastic nature of the growth of microstructurally short cracks. However, a considerably larger number of investigations (Kozin and Bogdanoff, 1981; Virkler et al., 1979; Lin and Yang, 1983; Ishikawa et a 1., 1987; Spencer and Tang, 1988) have been carried out for long-crack problems. Long cracks usually show smaller fluctuations in the crack-growth rates than short cracks. The two approaches taken for short cracks thus far are based either on Monte Carlo simulations (Kitamura and Ohtani, 1987, 1988) or on the randomization of empirical crack-growth equations (Cox and Morris, 1987). The approach taken here is based on the damage accumulation along grain boundaries and the critical damage required for failure under creep and creepfatigue conditions. 1 The fluctuation of the crack-growth rate is formulated with the fundamental reliability analysis (Thoft-Christensen and Baker, 1982), which is based on the variability of the damage accumulation and the critical damage of the grain boundaries. The model is calibrated and is then used to predict the crack initiation and early growth rate of short cracks under creep and creep-fatigue conditions.

\section{STOCHASTIC MODEL FOR CRACK INITIATION AND GROWTH}

For many polycrystalline alloys under creep or creep-fatigue conditions, cracks initiate and grow along preferential grain boundaries. This localization of the cracking sites is due to the operative high-temperature failure mechanisms. Growth and coalescence of cavities and grain-boundary sliding are examples of local failure mechanisms leading to grain-boundary cracking (Garofalo, 1965). The time required for the initiation of a crack differs between seemingly identical grain boundaries because of creep resistance and geometric differences. The crack-growth rate is also dependent on such things as the grain-boundary orientation with respect to the loading axis, the distance between triple points, and the distribution of the precipitates and ledges on the boundaries. The highly random crack initiation and growth processes are created by the presence of microstructural inhomogeneities. The local loading conditions along grain boundaries are also random because of creep deformation anisotropy, grain shape, and constraints. A simplified stochastic model is proposed for predicting the probability of crack initiation and growth under creep and creep-fatigue conditions. This model takes into consideration material inhomogeneities, microstructure geometric variations, and local loading randomness.

The assumptions included in the model are that (1) cracks grow only along grain boundaries, (2) crack length is measured as the projected length on a plane perpendicular to the loading axis, (3) projected grain-boundary length between adjacent triple points $d$ is a random variable with density function $f(d)$, and (4), the width of the crack is ignored. The two-dimensional model can be modified, if necessary, to a three-dimensional model by converting the

1The term "creep fatigue", as used here, implies a reversed cyclic creep deformation at high temperature under which creep dominates the failure process. A discussion of synergistic creep-fatigue interaction is beyond the scope of this report. 
crack length into crack area. It is also assumed that crack initiation and growth occur in a discrete manner, increasing in segments that are equal to the distance $d$ between two triple points after a certain time $t$ (fig. 1 ). It has been observed experimentally that grain-boundary triple points act as crack arresters (Ohtani et al., 1984). Therefore, crack growth is usually halted at triple points or grain-boundary kinks (sharp bends) until enough damage is accumulated in the adjacent grain boundary for the crack to extend again. It is postulated that crack initiation and growth occur when the accumulated damage $\phi$ equals a critical value $\phi_{c}$. The critical damage $\phi_{c}$ can be interpreted as the resistance of a particular grain boundary to cracking, which is a random variable. The density function of the critical damage $\phi_{C}$ is given by $g\left(\phi_{C}\right)$. The damage accumulation $\phi$ is the local driving failure parameter for a particular grain boundary. The critical damage $\phi_{c}$ is independent of the applied stress but $\phi$ is strongly related to $i t$. The damage accumulation $\phi$ is the integral of the damage accumulation rate $\dot{\phi}$ :

$$
\phi=\int_{0}^{t} \dot{\phi} d t
$$

The damage rate $\dot{\phi}$ is a random variable that is a function of the local stress $\sigma_{1}$. The local stress state $\left.\sigma\right]$ is a function of the constant global applied stress $\sigma_{\mathrm{g}}$ and the crack length $\ell$. Assuming a steady-state failure process, the damage accumulation rate is taken to be independent of time.

$$
\phi=\dot{\phi} t
$$

The density function $k$ of $\phi$ is related to the density function of $\dot{\phi}$, $h\left(\dot{\phi} \mid \sigma_{g}, l\right)$ by

$$
k\left(\phi \mid \sigma_{g}, l\right)=1 / t \cdot h\left(\dot{\phi} \mid \sigma_{g}, \ell\right)
$$

If the grain boundary under consideration is adjacent to a crack, the failure is called crack growth. If the grain boundary is isolated from other cracked regions, the failure is called crack initiation.

This model is applicable, but not limited, to monotonic creep conditions. It can also be applied to time-dependent fatigue (i.e., creep-dominant fatigue). As an example, under a slow-fast fatigue loading (fig. 2) of 304 stainless steel at $973 \mathrm{~K}$ in vacuum, irreversible grain-boundary sliding was observed. This was due to the creep deformation in the tensile half of the cycle (Taira et al., 1978). Under those conditions, the intergranular crack initiation is associated with creep damage accumulation in the tensile half of the cycle. Thus, the time should be converted into the number of cycles and the local stress ol should be interpreted as an equivalent stress of the tensile half of the loading cycle.

This damage accumulation formulation is expressed in mathematical terms only. Physical explanation of the damage equation is discussed next. If one considers that the damage is associated with cavity growth, the damage function $\phi$ can be written in terms of the number and the radii of the cavities observed on a particular grain boundary. The damage function $\phi$ can be formulated as the ratio of the summation of cavity length over the grain-boundary length. Experimental observations have shown that the summation of the length 
of grain-boundary cavities is proportional to time (Yang, 1984). Hence, a physical meaning is given to the steady-state damage accumulation of equation (2). More sophisticated damage equations can, of course, replace equation (2), which can be written in terms of cavity initiation and growth laws.

\section{PROBABILITY OF CRACK INITIATION AND GROWTH}

\section{Crack Initiation}

As seen previously, failure on a specific grain boundary occurs when the damage accumulation exceeds a critical damage level. Let us now define a new variable $\phi_{m}$, known as the failure function, as the difference between $\phi_{c}$ and $\phi$ :

$$
\phi_{\mathrm{m}}=\phi_{\mathrm{c}}-\phi
$$

The failure criterion is simply reduced to $\phi_{m}=0$. Consequently, the probability of a crack initiating at a particular grain boundary $P_{f}(t)$ is the probability that $\phi_{m}$ is less than or equal to zero:

$$
P_{f}(t)=P\left(\phi_{m} \leq 0\right)
$$

The density function of the new random variable $\phi_{m}$ is given by $m_{0}\left(\phi_{m} \mid t, \sigma_{g}\right)$ for a given time $t$ and global stress $\sigma_{g}$. The density function $m_{0}$ is related to the density functions of the two independent random variables $\phi_{C}$ and $\phi$, by the following convolution integral:

$$
m_{0}\left(\phi_{m} \mid t, \sigma_{g}\right)=\int_{0}^{\infty} g\left(\phi_{m}+\phi\right) k\left(\phi \mid t, \sigma_{g}, l=0\right) d \phi
$$

Knowing that $\phi=\dot{\phi}$, then

$$
m_{0}\left(\phi_{m} \mid t, \sigma_{g}\right)=\int_{0}^{\infty} g\left(\phi_{m}+\dot{\phi} t\right) h\left(\dot{\phi} \mid \sigma_{g}, \ell=0\right) d \dot{\phi}
$$

If the density functions of $\phi_{C}$ and $\dot{\phi}$ are known, then the probability $P_{f}(t)$ for crack initiation at one particular grain boundary before time $t$ for a given global stress $\sigma_{\mathrm{g}}$ is given by

$$
P_{f}(t)=P\left(\phi_{m} \leq 0\right)=\int_{-\infty}^{0} m_{0}\left(\phi_{m} \mid t, \sigma_{g}\right) d \phi_{m}
$$

A polycrystalline material has many grain boundaries, which are potential crack initiation sites. The probability that $n$ number of cracks initiated in time $t$ for a total number of potential crack initiation sites $N$ is given by the following binomial distribution: 


$$
\left(P_{f}\right)_{n}=\frac{N !\left[P_{f}(t)\right]^{n}\left[1-P_{f}(t)\right]^{N-n}}{(N-n) ! n !}
$$

The expected value or mean number of crack initiations in a given time $t$ and its variance are given respectively by

$$
E(n)=N P_{f}(t)
$$

and

$$
\operatorname{VAR}=E\left([n-E(n)]^{2}\right)=N P_{f}(t)\left[1-P_{f}(t)\right]
$$

\section{Crack Growth}

The criterion for crack growth in terms of accumulated damage is similar to that for crack initiation. The crack-growth criterion still corresponds to the damage accumulation $\phi$ reaching a critical value, $\phi_{C}$; however, the damage accumulation rate is accelerated by the presence of a crack. The failure function $\phi_{m}$ of equation (4) for the grain boundary $i$ immediately adjacent to the crack tip is redefined for crack growth as

$$
\phi_{m}=\phi_{c}-\dot{\phi}_{j}\left(\ell, \sigma_{g}\right) t
$$

where $\dot{\phi}_{j}\left(\ell, \sigma_{g}\right)$ is the damage accumulation rate at grain boundary $i$, and $t$ is the time elapsed after the crack reaches the particular grain boundary $i$. Since crack growth occurs when $\phi_{m}=0$, the time interval $t_{i}$ required for the crack to travel the entire grain boundary $i$ is given by

$$
t_{i}=\phi_{C} / \dot{\phi}_{i}
$$

The density function of the time $t_{i}$ in terms of the density functions $g\left(\phi_{c}\right)$ and $h\left(\dot{\phi}_{j}\right)$ can be shown to be

$$
s\left(t_{j} \mid \sigma_{f}, l\right)=\int_{0}^{\infty} \dot{\phi}_{i} g\left(\dot{\phi}_{i} t_{i} \mid \sigma_{g}\right) h\left(\dot{\phi}_{j} \mid \sigma_{g}, l\right) d \dot{\phi}_{i}
$$

The crack-growth rate of a short crack is then given by

$$
d \ell / d t=d_{j} / t_{j}
$$

where $d_{j}$ is the projected distance between two triple points of grain boundary $i$. The density function of the crack-growth rate in terms of the density functions $s\left(t_{j}\right)$ and $f\left(d_{j}\right)$ of $t_{j}$ and $d_{j}$, respectively, is given by

$$
P_{g}\left(d l / d t \mid \sigma_{g}, l\right)=\int_{0}^{\infty} t_{i} f\left(d l / d t \cdot t_{i}\right) s\left(t_{i} \mid \sigma_{g}, l\right) d t_{i}
$$


The dainage accumulated before the grain boundary $i$ becomes adjacent to the crack tip is assumed negligible because it was shown experimentally that pre damage of stainless steel specimens has little effect on crack growth under creep and creep-fatigue conditions (Ohtani and Kitamura, 1986). A formulation that takes into consideration the predamage effect is described in the appendix.

\section{Normalization}

As seen previously, the damage accumulation rate $\dot{\phi}$ is a function of the local stress $\sigma_{1}$, which depends on the applied global stress $\sigma_{g}$ and crack length $\ell$. For simplicity, the following relation can be assumed:

$$
\sigma_{1}=K(u \mid \ell) \sigma_{g}
$$

where $K(u \mid \ell)$ is a stress concentration factor function of the crack length $\ell$ and microstructural randomness $u$. Under creep conditions, the damage accumulation rate can be taken to be a power function of the local stress

$$
\dot{\phi}=A \sigma_{1}^{\alpha}
$$

where $A$ and $\alpha$ are assumed to be material constants. Assuming a steadystate damage rate, the damage accumulation is then given as a function of the global stress and $K(u \mid l)$ by substituting equations (17) and (18) in equation (2):

$$
\begin{gathered}
\phi=\dot{\phi} t=A\left(K(u \mid \ell) \sigma_{g}\right) \alpha t \\
\phi=\bar{\phi} \bar{t}
\end{gathered}
$$

where $\bar{\phi}=A K(u \mid \ell) \alpha$

$$
E=\sigma_{g}^{\alpha} t
$$

Here, $\overline{\dot{\phi}}$ is a random variable because $K(u \mid l)$ is a random variable, but $\bar{\epsilon}$ is a deterministic variable. The density function $\hbar$ of the normalized damage accumulation rate is related to $h$ of $\dot{\phi}$ by

$$
\hbar(\bar{\phi})=\sigma_{g}^{\alpha} h(\dot{\phi})
$$

The probability of the crack initiation can be rewritten in terms of the normalized variables as

$$
P_{f}(E)=\int_{-\infty}^{0} \bar{m}_{0}\left(\phi_{m} \mid E\right) d \phi_{m}=\sigma_{g}^{\alpha} P_{f}
$$

where

$$
\bar{m}_{0}\left(\phi_{m} \mid E\right)=\int_{0}^{\infty} g\left(\phi_{m}+\overline{\dot{\phi}} \bar{t}\right) \bar{h}(\bar{\phi} \mid \ell=0) d \overline{\dot{\phi}}
$$


The density function of the crack-growth rate in terms of the normalized time interval $E_{j}=\sigma_{g}^{\alpha} t_{j}$ can be shown to be equal to

$$
\begin{gathered}
P_{g}(d l / d E \mid l)=\int_{0}^{\infty} E_{j} f\left(d l / d E \cdot E_{i}\right) \bar{s}\left(E_{i} \mid l\right) d E_{i} \\
\bar{s}\left(E_{j} \mid l\right)=\sigma_{g}^{\alpha} s\left(t_{j} \mid \sigma_{g}, l\right)
\end{gathered}
$$

Therefore, the actual density function is related to the normalized density function by

$$
P_{g}\left(d \ell / d t / \sigma_{g}, l\right)=\left(1 / \sigma_{g}\right)^{\alpha} P_{g}(d \ell / d E \mid \ell)
$$

It should be noted that $\bar{P}_{f}$ and $\bar{P}_{g}$ are independent of $\sigma_{g}$. The terms $P_{f}$ and $\mathrm{Pg}_{\mathrm{g}}$ are easily calculated for any arbitrarily applied global stress $\sigma_{\mathrm{g}}$ by equations (23) and (27), respectively.

\section{APPLICABILITY OF STOCHASTIC MODEL}

Few experiments have been carried out to determine crack initiation and growth of short cracks at high temperature. Because of the small data base available, only the applicability of the stochastic model is discussed. This model is applied to two different data sets for which experimental data are available. Both experiments were carried out on smooth specimens of 304 stainless steel with an average grain diameter of $40 \mu \mathrm{m}$. The cracks initiated and grew on the specimen surface. In the first experiment (Ohtani et al., 1983), the number of crack initiations was monitored under monotonic creep at $923 \mathrm{~K}$ in air at applied stress levels of $98.1 \mathrm{MPa}$ and $147.1 \mathrm{MPa}$. In the second experiment, crack initiation and growth were measured under slow-fast fatigue (Ohtani et al., 1986). The total strain range was equal to 1 percent and the strain rates in tension and compression were $10^{-3}$ percent/s and 1 percent/s, respectively, at $923 \mathrm{~K}$ in vacuum.

For the model calibration, the density functions of the damage rate $h\left(\dot{\phi} \mid \sigma_{g}, l\right)$ and of the critical damage $g\left(\phi_{C}\right)$ should be determined from actual experimental data. However, standard density functions are assumed in this study because of the limited data available. Since $\phi_{c}$ and $\dot{\phi}$ are positive variables, the two-parameter Weibull and logarithmic normal distributions are adopted here for $\phi_{C}$ and $\dot{\phi}$, respectively, and are given below for completeness:

$$
g\left(\phi_{C}\right)=\frac{\beta}{b}\left(\frac{\phi_{c}}{b}\right)^{\beta-1} e^{-\left(\frac{\phi_{c}}{b}\right)^{\beta}}
$$




$$
h\left(\dot{\phi} \mid \sigma_{g}, l\right)=\frac{1}{\sqrt{2 \pi} \sigma_{\ln \dot{\phi}}} e^{-\frac{1}{2}\left[\frac{\ln \left(\frac{\dot{\phi}}{m_{\dot{\phi}}}\right)}{\sigma_{\ln \dot{\phi}}}\right]^{2}}
$$

where $\beta$ and $b$ are material constants, $m_{\dot{\phi}}$ is the mean value of $\dot{\phi}$, and $\sigma \ln \dot{\phi}$ is the standard deviation of the $\ln \dot{\phi}$. The normalized function of the damage accumulation rate $\hbar(\bar{\phi} \mid \ell)$ and the density function of the damage accumulation $k\left(\phi \mid \sigma_{g}, t, l\right)$, which are derived from equation (29), are given by

$$
\begin{aligned}
& \bar{h}(\bar{\phi} \mid \ell)=\frac{1}{\sqrt{2 \pi} \sigma_{\bar{\phi}}} e^{-\frac{1}{2}\left[\frac{\ln \left(\frac{\dot{\phi}}{m_{\dot{\phi}}}\right)}{\sigma_{\ln }}\right]^{2}} \\
& \hbar(\overline{\dot{\phi}} \mid \ell)=\frac{1}{\sqrt{2 \pi} \sigma_{\ln \overline{\dot{\phi}}}} e \\
& -\frac{1}{2}\left[\frac{\ln \left(\frac{\phi}{m \dot{\phi} t}\right)}{\sigma \ln \dot{\phi}}\right]^{2} \\
& k\left(\phi \mid \sigma_{g}, t, l\right)=\frac{1}{\sqrt{2 \pi} \sigma_{\ln \phi^{\phi}}} \mathrm{e}
\end{aligned}
$$

where $m_{\bar{\phi}}$ is the mean value of $\overline{\dot{\phi}}$.

The exponent $\alpha$, in equation (23), is given by $(\gamma+1)$ where $\gamma$ is the creep exponent of the material. The choice of $\alpha$ to be equal to $(y+1)$ is based on the assumption that the damage accumulation is proportional to the local strain energy density rate $U_{0 \times} \dot{\varepsilon} \sigma$, which is proportional to $\sigma(\gamma+1)$ for a power-law creep material. The creep exponent $Y$ of 304 stainiess steel is equal to 7 under monotonic creep conditions at $923 \mathrm{~K}$ in air (Kitamura and Ohtani, 1988).

\section{Crack Initiation}

The constants in the density functions of the critical damage and the damage rate are calibrated with actual experimental data under monotonic creep at $98.1 \mathrm{MPa}$. The constants are adjusted for the theoretical expected value of the number of crack initiation sites $E(n)$ to fit the actual data Cohtani et al., 1983). The total number of potential crack initiation sites $N$ is approximately equal to $900 \mathrm{sites} / \mathrm{mm}^{2}$ for this material. The constants obtained from the calibration are listed in table 1 . The expected value of the crack initiation sites is plotted versus time and compared with the experimental results (fig. $3(a)$ ). The rate of change of the expected value $E(n)$ increases with increasing time. Also shown is the scatter band of the mean value, plus and minus one standard deviation. The calibration fits the data well in view of the restriction of the assumed density functions for $\dot{\phi}$ and $\phi_{C}$. 
As a check to the validity of the calibration, the expected value of the number of cracks in tiated is calculated for a different stress level and then compared with experimental data. Figure $3(b)$ shows the predicted results under creep conditions at an applied stress level of $147.1 \mathrm{MPa}$. The experimental results are shown to be within one standard deviation and are always lower than the predicted mean value $E(n)$. The stochastic model predicts the mean-crack initiation lives to be within an average deviation of about 10 percent.

\section{Short-Crack Growth}

The stochastic model for early crack growth is applied to 304 stainless steel under creep-fatigue condition at $923 \mathrm{~K}$ (Ohtani et al., 1986). The constants $\beta$ and $b$ of $g\left(\phi_{C}\right)$ are assumed to have the same values as in the previous crack initiation study under creep condition because the variability of the critical damage is only material dependent. The acceleration of the damage accumulation rate $h(\dot{\phi})$, caused by the presence of a crack, is taken to be a simple linear variation of the mean with crack length $\ell$ as given by

$$
m_{\dot{\phi}}=C_{0}+C_{1} \ell
$$

The standard deviation $\sigma \ln \dot{\phi}$ is assumed to be independent of $\ell$ for simplicity. The constant $C_{0}$ corresponds to the mean value of $\dot{\phi}$ for $\ell=0$, which can be determined easily from crack initiation data as described in the preceding section. The constant $C_{1}$ is calibrated by using long crack-growth rate data of notched specimens with crack length greater than $1 \mathrm{~mm}$. Note that $C_{1}$ is calibrated by using long-crack notched specimens that are different from the smooth, short-crack specimens. The calibrated constants $C_{0}$ and $C_{1}$ are listed in table II. The distribution of the grain-boundary length $f(d)$ is calculated by assuming a normal distribution with an average grain length of $0.02 \mathrm{~mm}$ and a standard deviation of $0.005 \mathrm{~mm}$.

The sensitivity of the damage accumulation prior to the dominant crack's reaching a particular grain boundary is investigated first with the formulation given in the appendix. The values of the constants $C_{1}$ and $C_{0}$ used in this study are listed in table II. The analysis reveals the probability that the crack-growth rate $\mathrm{d} l / \mathrm{dt}$ is insensitive to the predamage time $t_{0}$ for $\ell \geq 0.03 \mathrm{~mm}$. When the crack reaches the grain boundary under consideration, the damage accumulation due to stress concentration is accelerated to a much faster rate than the predamage rate. This is due to the large difference between the values of $C_{1}$ and $C_{0}$. These calculations are consistent with experimental observations (Ohtani and Kitamura, 1986) indicating that, once a crack appears, the overwhelming damage is localized in the grain boundary immediately adjacent to the crack tip. The predicted cumulative probability distributions of short crack-growth rates for two different crack lengths of $0.03 \mathrm{~mm}$ and $0.06 \mathrm{~mm}$ are given in figure 4 . The experimental results are shown for purposes of comparison. For the given density distributions of $\phi_{C}$ and $\dot{\phi}$, the stochastic model gives the same range of crack-growth rates as the experimental data. The predicted distributions show good correlation with the experimental results for higher crack-growth rates. For lower crack-growth rates, the small disagreement may be due in part to the difficulty of monitoring extremely slow crack-growth rates. The dependence of the crack-growth rate on crack lengths is plotted in figure 5. The mean crack-growth rates with the 10 percent and 90 percent confidence lines are shown for crack lengths ranging 
fi Jm $0.03 \mathrm{~mm}$ to $0.2 \mathrm{~mm}$. Also shown are the experimental upper and lower crackglowtli rates of appioximately 50 initially monitored cracks. The predicted mean value falls between the upper and lower values of the experimental crackgrowth rates. The predicted 90 percent and 10 percent confidence 1 ines follow closely the experimental upper and lower limits, respectively.

\section{SUMMARY OF RESULTS}

A simplified stochastic model was proposed to predict the distribution of the initiation of cracks and their early growth under creep and creep-fatigue conditions. The model was formulated by using concepts of damage accumulation and critical damage required for grain-boundary failure. The density functions of the damage rate and the critical damage were assumed to have standard forms (log-normal and Weibull distributions, respectively). The mean and the variance were calibrated by comparing the predicted results with experimental data. Damage history and the presence of a dominant crack were introduced in a simple form that influenced the mean of the damage accumulation rate. The standard deviation of the damage rate was assumed constant in this study. The model predicted mean-crack initiation lives at different stress levels within an average deviation of about 10 percent. The cumulative distributions of the crack-growth rates under creep-fatigue conditions for different crack lengths followed closely the variability of the experimental data.

Although the proposed model gave good predictions, there is a need for model improvements and sensitivity studies of the damage distributions and their dependence on crack length and predamage. The damage accumulation should be formulated from a micromechanics, or cavity growth, law. The crack-growth behavior was oversimplified by allowing for only one dominant propagating crack. Multiple cracks and crack coalescence, based on the formulation in the appendix, should be considered. Damage recovery must be accounted for in the formulation for more complex loading conditions with compressive segments. The effect of predamage formulation in the appendix must be verified with additional experiments. 


\section{APPENDIX - PREDAMAGE EFFECT ON CRACK GROWTH}

The failure function $\phi_{m}$ of equation (4) with predamage is now expressed as

$$
\phi_{m}=\phi_{C}-\phi_{0 i}-\dot{\phi}_{j}\left(l, \sigma_{g}\right) t
$$

where $\dot{\phi}_{j}\left(l, \sigma_{g}\right)$ is the damage accumulation rate at boundary $i$ when the crack is immediately adjacent to that particular boundary, $t$ is the time elapsed after the crack reaches the particular grain boundary $i$, and $\phi_{c}$ is the critical damage needed for the grain-boundary failure. The function $\phi_{0 i}$ is the damage accumulated at that grain boundary prior to becoming adjacent to the crack tip. In other words, $\phi_{0 i}$ represents the damage state of the grain boundary prior to its being located adjacent to the main crack. Assuming that the dominant crack affects only the adjacent grain boundary, the damage $\phi_{0} i$ can be expressed as a function of the damage accumulation rate:

$$
\begin{aligned}
\phi_{0 i} & =\dot{\phi}_{i}\left(\sigma_{g}, l=0\right) \sum_{j=0}^{i-1} t_{j} \\
& =\dot{\phi}_{i}\left(\sigma_{g}, l=0\right) t_{0}
\end{aligned}
$$

where $t_{j}$ is the time interval for the crack to travel the entire length of grain boundary $j$. Summation of $t_{j}$ is equal to the total time $t_{0}$ elapsed before the crack reaches the grain boundary $i$. The density $q\left(\phi_{t}\right)$ of $\left(\phi_{0 j}+\dot{\phi}_{j} t\right)$ is given by:

$$
q\left(\phi_{t} \mid \sigma_{g}, l, t, t_{0}\right)=\int_{0}^{\infty} h_{0 i}\left(\frac{\phi_{t}-\dot{\phi}_{j} t}{t_{0}}, \dot{\phi}_{i}\right) \frac{1}{t_{0}} d \dot{\phi}_{i}
$$

where $h_{0 i}\left(\dot{\phi}_{j}\left(\sigma_{g}, l=0\right), \dot{\phi}_{j}\left(\sigma_{g}, l\right)\right)$ is the joint probability density of $\dot{\phi}_{j}\left(\sigma_{g}, l=0\right)$ and $\dot{\phi}_{j}\left(\sigma_{g}, l\right)$. The density function $m\left(\phi_{m}\right)$ of the failure function is therefore given by

$$
m\left(\phi_{m} \mid \sigma_{g}, l, t, t_{0}\right)=\int_{0}^{\infty} g\left(\phi_{m}+\phi_{t}\right) q\left(\phi_{t} \mid \sigma_{g}, l, t, t_{o}\right) d \phi_{t}
$$

The cumulative probability function $s\left(t_{i} \mid \sigma_{g}, l, t_{0}\right)$ of the time interval required for the crack to travel the entire length of grain boundary $i$ is given by

$$
S\left(t_{j} \mid \sigma_{g}, l, t_{0}\right)=\int_{-\infty}^{0} m\left(\phi_{m}, l, t_{j}, t_{o}\right) d \phi_{m}
$$

The density function of the crack-growth rate de/dt is given by equation (16) with $s\left(t_{j} \mid \sigma_{g}, l, t_{0}\right)$ being the derivative of equation (A5). However, a special 
constraint must be placed on the function $s\left(t_{j}\right)$. It is assumed that no crack growlli occurs on a particular grain boundary unless that boundary is immediately adjacent to the main crack. Therefore, $s\left(t_{i}\right)$ for $t_{j} \leq 0$ must be zero. The following two requirements are needed to satisfy the positive constraint on $s\left(t_{i}\right)$ for $t_{j}=0$ :

(1) The function $\phi_{0}$ i does not exceed $\phi_{C}$ at grain boundary i before the crack reaches that grain boundary.

(2) If $\phi_{0} i$ is greater than $\phi_{c}$ at grain boundary $i$, the boundary acts as a potential crack. The main crack instantaneously jumps to the next boundary, $i+1$, when it reaches grain boundary $i$.

Case (1) is consistent with the assumption shown in figure 6(a) for a single crack growth. Case (2) gives future directions for handling crack coalescence for multiple crack growth (fig. 6(b)). The procedure for adjusting $s\left(t_{i}\right)$ to be always positive for case (1) is similar to the adjustment of the density function of strength after proof-testing (Brent-Hall, 1988). The adjusted function, shown schematically in figure $7(\alpha)$, is given by

$$
s^{\prime}\left(t_{i} \mid \sigma_{g}, l, t_{0}\right)=\left\{\begin{array}{cc}
0 & t_{i} \leq 0 \\
\frac{s\left(t_{i}\right)}{1-s\left(t_{i}=0\right)} & t_{i}>0
\end{array}\right.
$$

For case (2), the negative part of $t_{i}$ is lumped in a delta function at $0^{+}$with a magnitude equal to $s\left(t_{j}\right)$. The adjusted density function is then given by

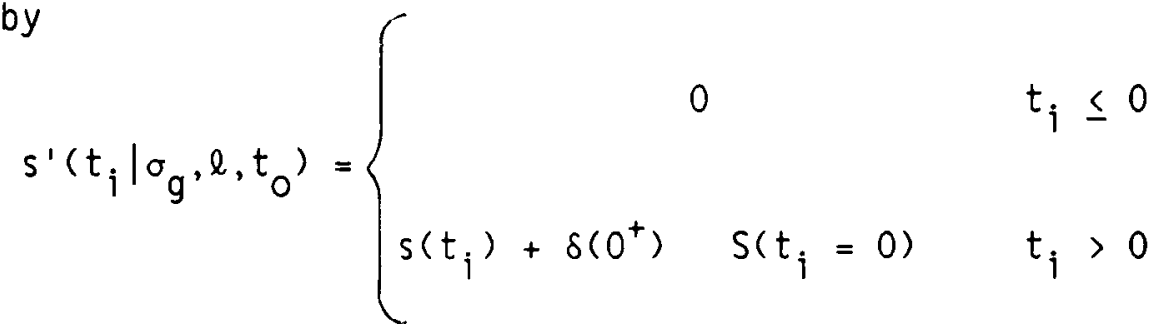

This relation is illustrated in figure $7(b)$. The density functions $\mathrm{Pg}_{\mathrm{g}}$, for cases (1) and (2), are schematically drawn in figure 8. For both cases, the crack growth accelerates as the historical time to increases. The infinite crack-growth rate, $\mathrm{dl} / \mathrm{dt}=\infty$ ( $\mathrm{fig} .8(\mathrm{~b})$ ), corresponds to the coalescence of the main crack with a potential crack. Crack coalescence is an important phenomenon that can shorten creep life drastically. However, the exact solution is beyond the scope of this report because a multiple crack-growth model is required. 


\section{REFERENCES}

1. Ohtani, R.; and Nakayama, S.: Growth and Distribution of Microcracks at the Surface of Smooth Specimen of 304 Stainless Steel in Creep and Effect of High Temperature Oxidation (in Japanese). J. Soc. Mater. Sci. Jpn., vol. 32, no. 357, June 1983, pp. 635-639.

2. Ontani, R.; Kinami, T.; and Sakamoto, H.: Small Crack Propagation in High Temperature Creep-Fatigue of 304 Stainless Steel (in Japanese). Nippon Kikai Gakkai Ronbunshu A Hen (Trans. JSME), vol. 52, no. 480, Aug. 1986, pp. 1824-1830.

3. Ohtani, R.; and Kitamura, T.: Crack Propagation Behavior and Fatigue Life Under Creep-Fatigue Interaction Condition. Role of Fracture Mechanics in Modern Technology, G.C. Sih, H. Nisitani, and T. Ishihara, eds., North Hol1 and, 1987, pp. 353-367.

4. Kozin, F.; and Bogdanoff, J.L.: A Critical Analysis of Some Probabilistic Models of Fatigue Crack Growth. Eng. Fract. Mech., vol. 14, no. 1, 1981, pp. 59-89.

5. Virkler, D.A.; Hillberry, B.M.; and Goel, P.K.: The Statistical Nature of Fatigue Crack Propagation. J. Eng. Mater. Technol., vol. 101, no. 2, Apr. 1979, pp. 148-153.

6. Lin, Y.K.; and Yang, J.N.: On Statistical Moments of Fatigue Crack Propagation. Eng. Fract. Mech., vol. 18, no. 2, 1983, pp. 243-256.

7. Ishikawa, H.; Tsurui, A.; and Kimura, H.: Stochastic Fatigue Crack Growth Model and Its Wide Applicability in Reliability-Based Design. Statistical Research on Fatigue and Fracture (Current Japanese Materials Research, vol. 2), T. Tanaka, S. Nishijima, and M. Ichikawa, eds., Elsevier Applied Science, 1987, pp. 45-58.

8. Spencer, B.F., Jr.; and Tang, J.: Stochastic Modeling of Fatigue Crack Growth. Probabilistic Methods in Civil Engineering, P.D. Spanos, ed., American Society of Civil Engineers, New York, 1988, pp. 25-28.

9. Kitamura, T.; and Ohtani, R.: Numerical Simulation of Microstructurally Short Crack Propagation in Creep (in Japanese). Nippon Kikai Gakkai Ronbunshu A Hen (Trans. JSME), vol. 53, no. 490, June 1987, pp. 1064-1070.

10. Kitamura, T.; and Ohtani, R.: Creep Life Prediction Based on Stochastic Model of Microstructurally Short Crack Growth. NASA TM-100245, 1988.

11. Cox B.N.; and Morris, W.L: A Probablistic Model of Short Fatigue Crack Growth. Fatigue Fract. Eng. Mater. Struct., vol. 10, no. 5, 1987 , pp. $419-428$.

12. Thoft-Christensen, P.; and Baker, M.J.: Structural Reliability Theory and its Application. Springer-Verlag, 1982.

13. Garofalo, F.: Fundamentals of Creep and Creep-Rupture in Metals. Macmillan, 1965. 
14. Ohtani, R.; Nakayama, S.; and Taira, T.: Applicability of Creep J-Integral to Microcrack Propagation of Creep in 304 Stainless Steel (in Japanese).

J. Soc. Mater. Sci. Jpn., vol. 33, no. 368, May 1984, pp. 590-595.

15. Taira, S.; Fujino, M.; and Yoshida, M.: Grain Boundary Sliding in Isothermal and Thermal Fatigue of 304 Stainless Steel (in Japanese). J. Soc.

Mater. Sci. Jpn., vol. 27, no. 296, May 1978, pp. 447-453.

16. Yang, M.S.: Study of Grain Boundary Cavitation of High Purity Copper in High Temperature Fatigue and Creep. Doctoral Thesis, Northwestern University, 1984 .

17. Brent-Hall, W.: Reliability of Service-Proven Structures. J. Struct. Eng., vol. 114, no. 3, Mar. 1988, pp. 608-624.

TABLE I. - CALIBRATED CONSTANTS FOR DISTRIBUTIONS OF $\phi_{C}, \phi$, AND $\phi$ FOR CRACK INITIATION ANALYSIS FOR MONOTONIC CREEP OF 304 STAINLESS STEEL

\begin{tabular}{|c|c|c|}
\hline $\begin{array}{c}\text { Constarits for } \\
\text { density function } \\
\text { of critical } \\
\text { damage (Eq. 28), } \\
g\left(\Phi_{c}\right)\end{array}$ & $\begin{array}{c}\text { Constants for density } \\
\text { function of damage } \\
\text { accumulated (Eq. 29), } \\
h(\phi)\end{array}$ & $\begin{array}{c}\text { Constants for normalized } \\
\text { density function of } \\
\text { damage accumulated } \\
\text { (Eq } 30) \\
\dot{h}(\phi)\end{array}$ \\
\hline $\begin{array}{l}\beta=2 \\
b=10\end{array}$ & $\begin{array}{l}\sigma_{1 n \phi}=1.0 \\
m_{\phi}=3.4 \times 10^{-4} \\
\left(\sigma_{g}=98.1 \mathrm{MPa}\right)\end{array}$ & $\begin{array}{l}\sigma_{n \phi}=1.0 \\
m_{\phi}=3.9 \times 10^{-20}\end{array}$ \\
\hline
\end{tabular}

TABLE II . - CALIBRATED CONSTANTS FOR

DISTRIBUTIONS OF $\phi_{C}$ AND $\phi$ FOR

CRACK-GROWTH ANALYSIS UNDER

CREEP-FATIGUE CONDITIONS OF

304 STAINLESS STEEL

\begin{tabular}{|c|c|}
\hline $\begin{array}{c}\text { Constants for } \\
\text { density function } \\
\text { of critical } \\
\text { damage (Eq. 28), } \\
g\left(\Phi_{c}\right)\end{array}$ & $\begin{array}{c}\text { Constants for density } \\
\text { function of damage } \\
\text { accumulated for crack } \\
\text { growth as a function } \\
\text { of crack length } e \\
\text { (Eq } 29) \\
\text { h( }\left(\Phi \mid \sigma_{g}, e\right)\end{array}$ \\
\hline $\begin{array}{l}\beta=2 \\
b=10\end{array}$ & $\begin{aligned} \mathrm{m}_{1 n \phi} & =c_{0}+c_{1} e \\
c_{0} & =0.008 \\
c_{1} & =1.08 \\
\sigma_{1 n \phi} & =1.0\end{aligned}$ \\
\hline
\end{tabular}



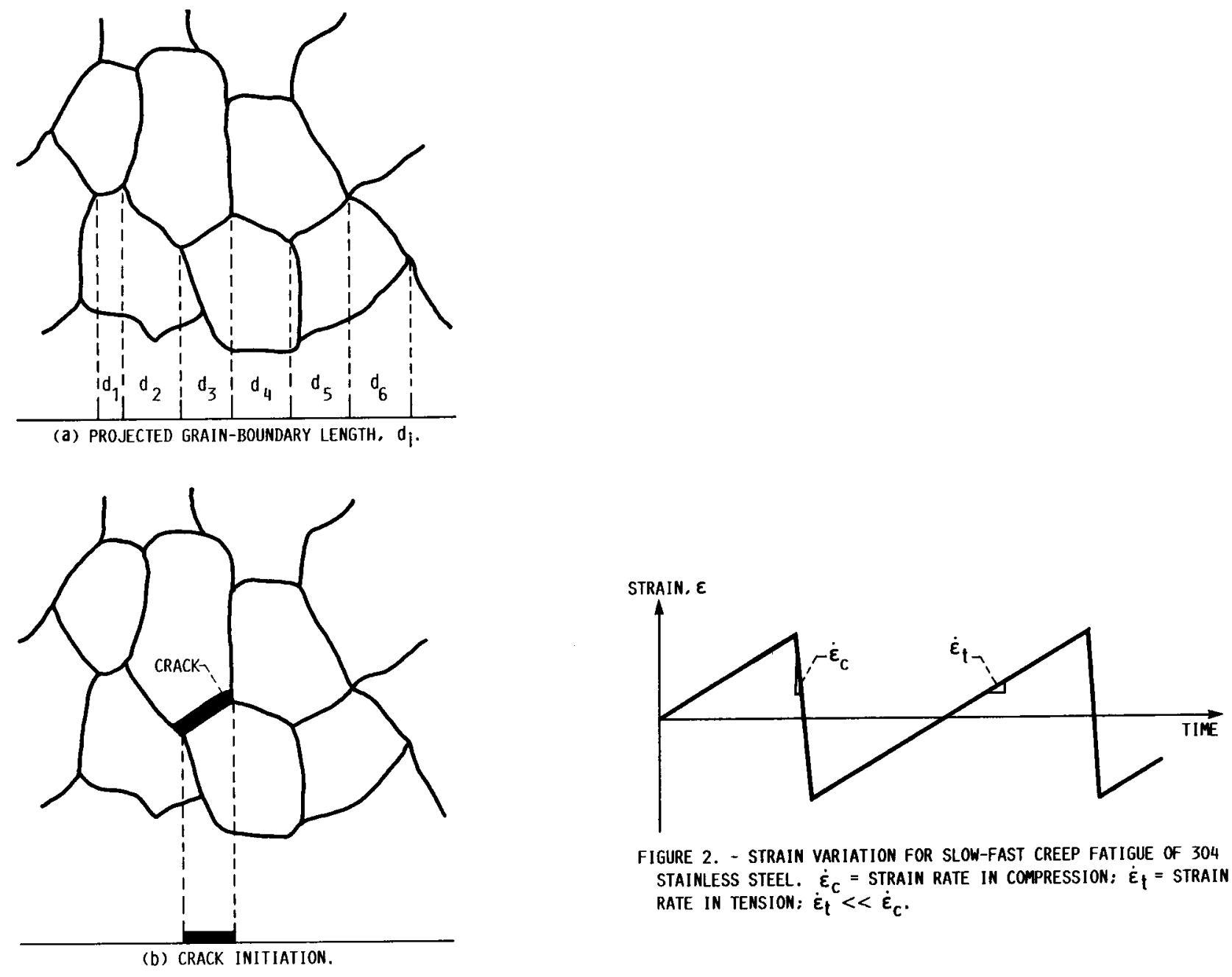

FIGURE 2. - STRAIN VARIATION FOR SLOW-FAST CREEP FATIGUE OF 304 STAINLESS STEEL. $\dot{\varepsilon}_{\mathrm{c}}=$ STRAIN RATE IN COMPRESSION: $\dot{\varepsilon}_{\mathrm{q}}=$ STRAIN RATE IN TENSION: $\dot{\varepsilon}_{\mathrm{t}}<<\dot{\varepsilon}_{\mathrm{c}}$.

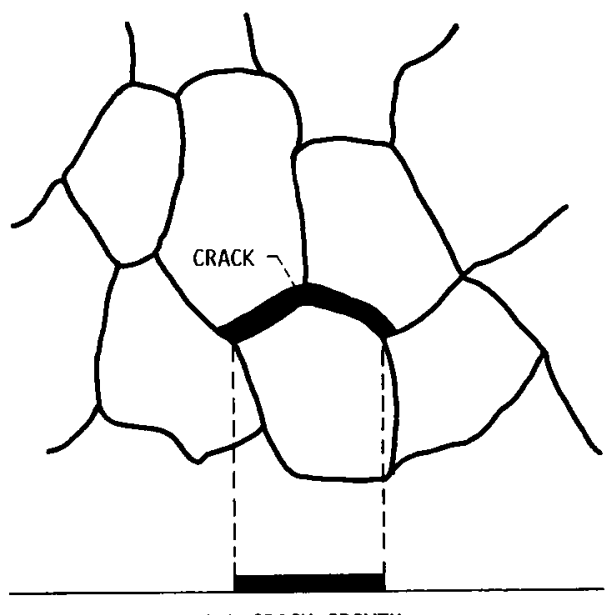

(c) CRACK GROWTH.

FIGURE 1. - SCHEMATIC VIEWS OF CRACK INITIATION AND GROWTH.

15 

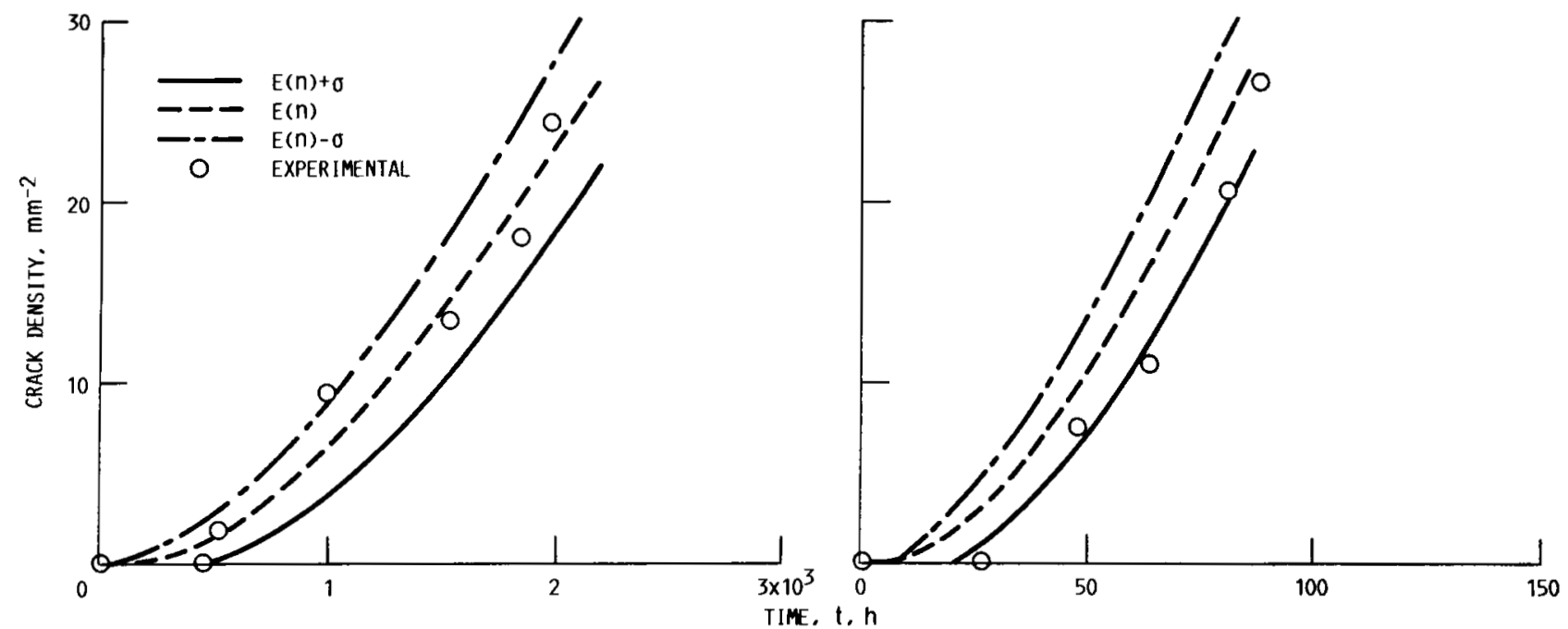

(a) CAL IBRATED. GLOBAL STRESS LEVEL, $98.1 \mathrm{MPA}$.

(b) PREDICTED. GLOBAL STRESS LEVEL, 147.1 MPA.

FIGURE 3. - CRACK-INITIATED DENSITY IN MONOTONIC CREEP OF 304 STAINLESS STEEL. S23 K IN AIR. E( $n$ ) = MEAN NUMBER OF INITIATED CRACKS: $\sigma=$ STANDARD DEVIATION

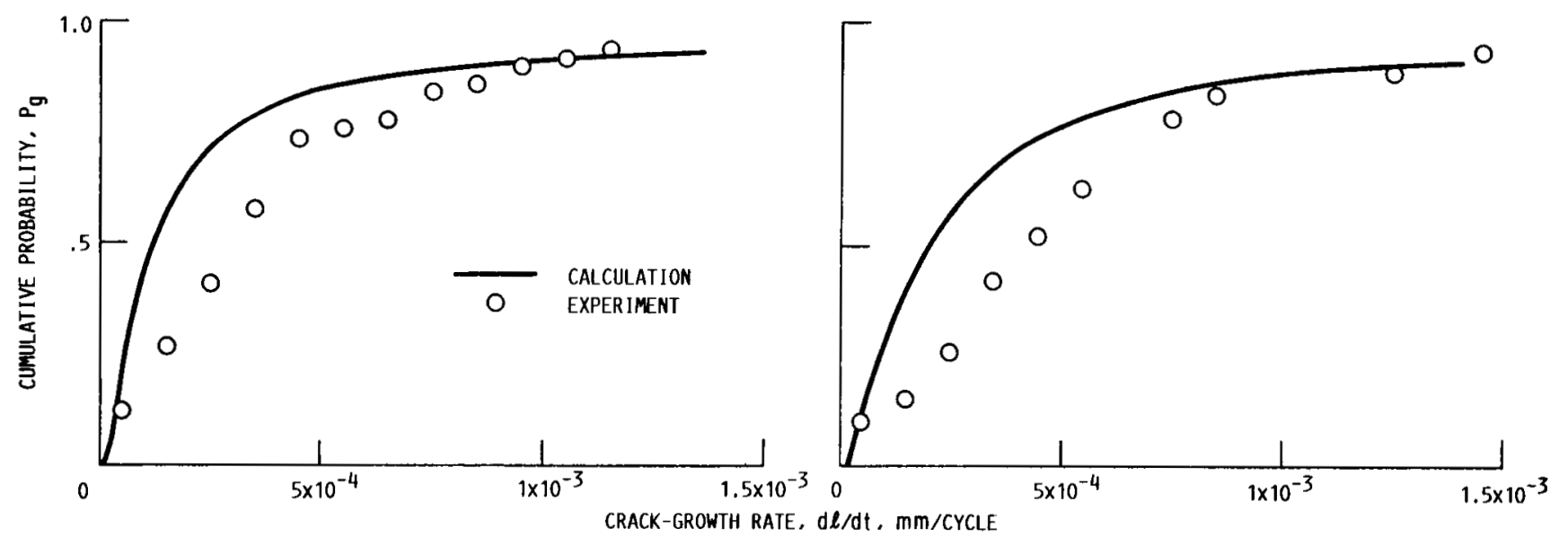

(a) CRACK LENGTH, $\ell=0.03 \mathrm{~mm}$.

(b) CRACK LENGTH, $\boldsymbol{l}=0.06 \mathrm{~mm}$.

FIGURE 4. - CUMULATIVE DENSITY FUNCTIONS OF CRACK-GROWTH RATE OF 304 STAINLESS STEEL FOR TWO CRACK LENGTHS UNDER CREEPFATIGUE CONDITION. $923 \mathrm{~K}$ IN VACUUM: SLOW-FAST FATIGUE: STRAIN RANGE, $\Delta \varepsilon, 1$ PERCENT. 


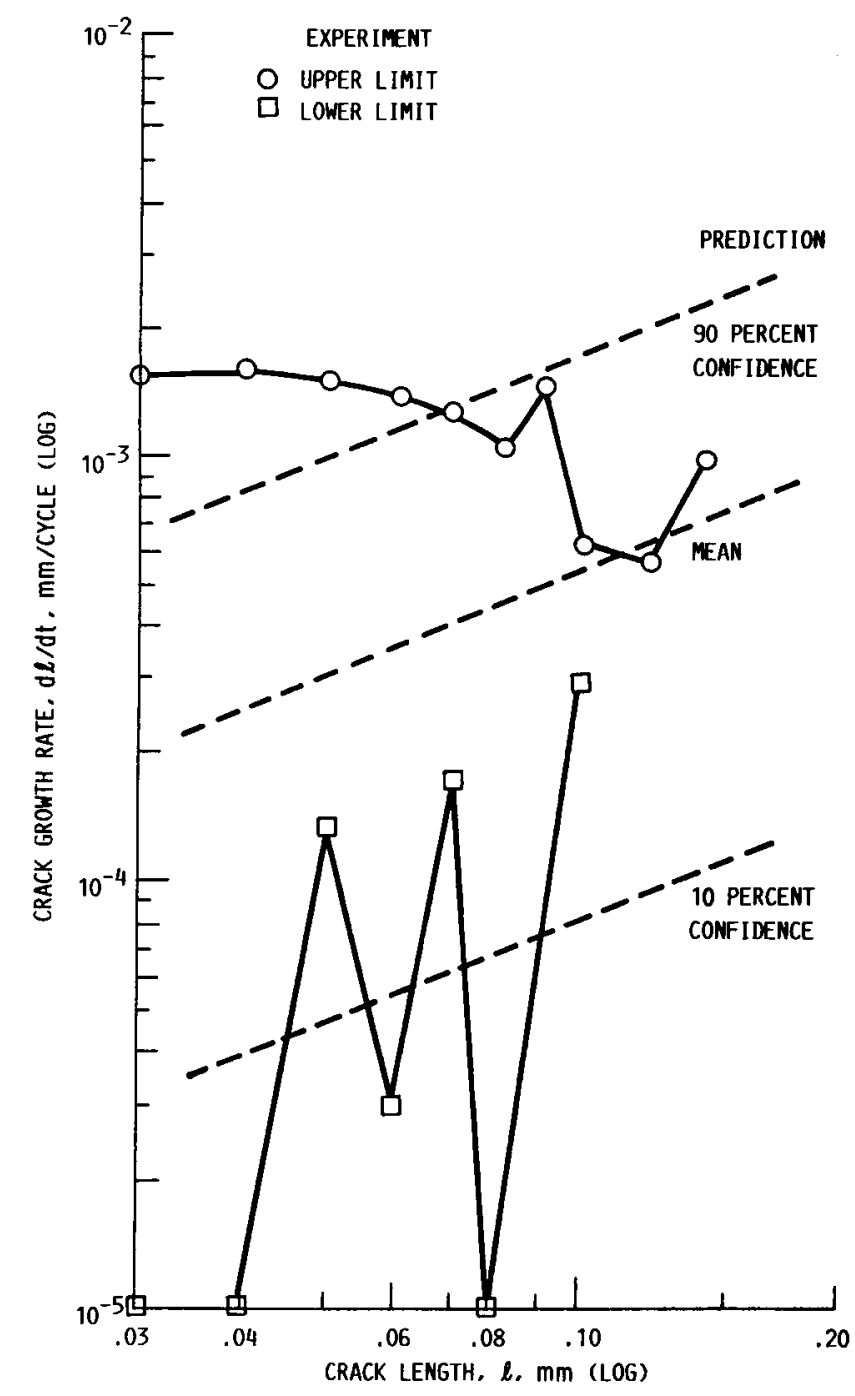

FIGURE 5. - COMPARISON OF PREDICTED AND EXPERIMENTAL VARIATION OF CRACK-GROWTH RATE OF 304 STAINLESS STEEL AS FUNCTION OF CRACK LENGTH UNDER CREEP-FATIGUE CONDITION. $923 \mathrm{~K}$ IN VACUUM: SLOW-FAST FATIGUE; STRAIN RANGE, $\Delta E$, 1 PERCENT.

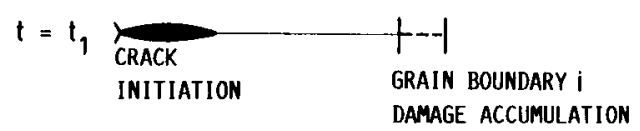

$t=t_{2}$

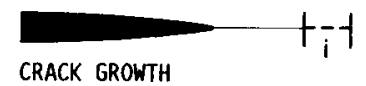

$\mathrm{t}=\mathrm{t}_{3}$ CRACK GROWTH

(a) FOR SINGLE CRACK GROWTH.

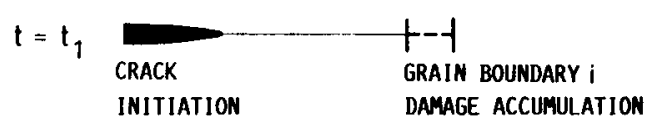
$t=t_{2} \underset{\text { CRACK GROWTH }}{i}$
CRACK INITIATION AND GROWTH

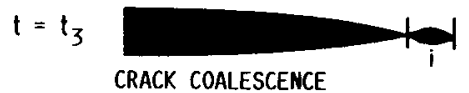

(b) FOR CRACK COALESCENCE.

FIgURE 6. - SCHEMATIC VIEWS OF CRACK-GROWTH PROCESS. $t_{1}<t_{2}<t_{3}$. 


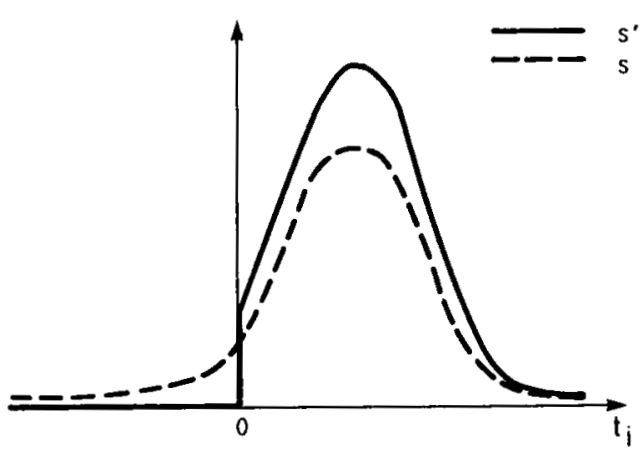

(a) FOR SINGLE CRACK GROWTH.

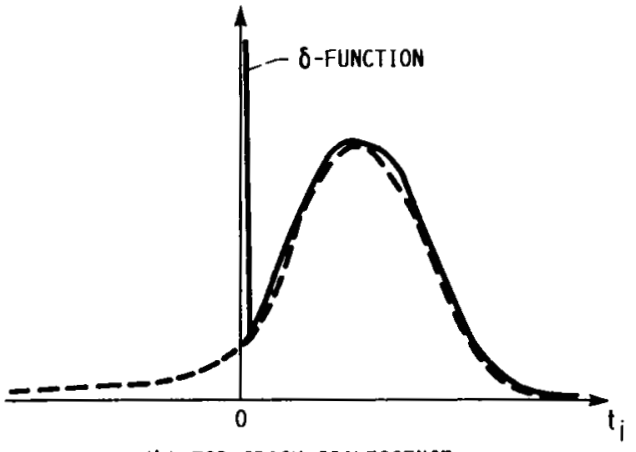

(b) FOR CRACK COALESCENCE.

FIGURE 7. - DIAGRAMS OF $s\left(t_{j}\right)$ AND $s^{\prime}\left(t_{i}\right)$ DENSITY FUNCTIONS OF TIME INTERVAL $t_{i}$. THE IMPOSSIBILITY OF CRACK GROWTH BEFORE $t_{i}=0$ IS REPRESENTED BY CORRECTED DENSITY FUNCTION $s^{\prime}$.

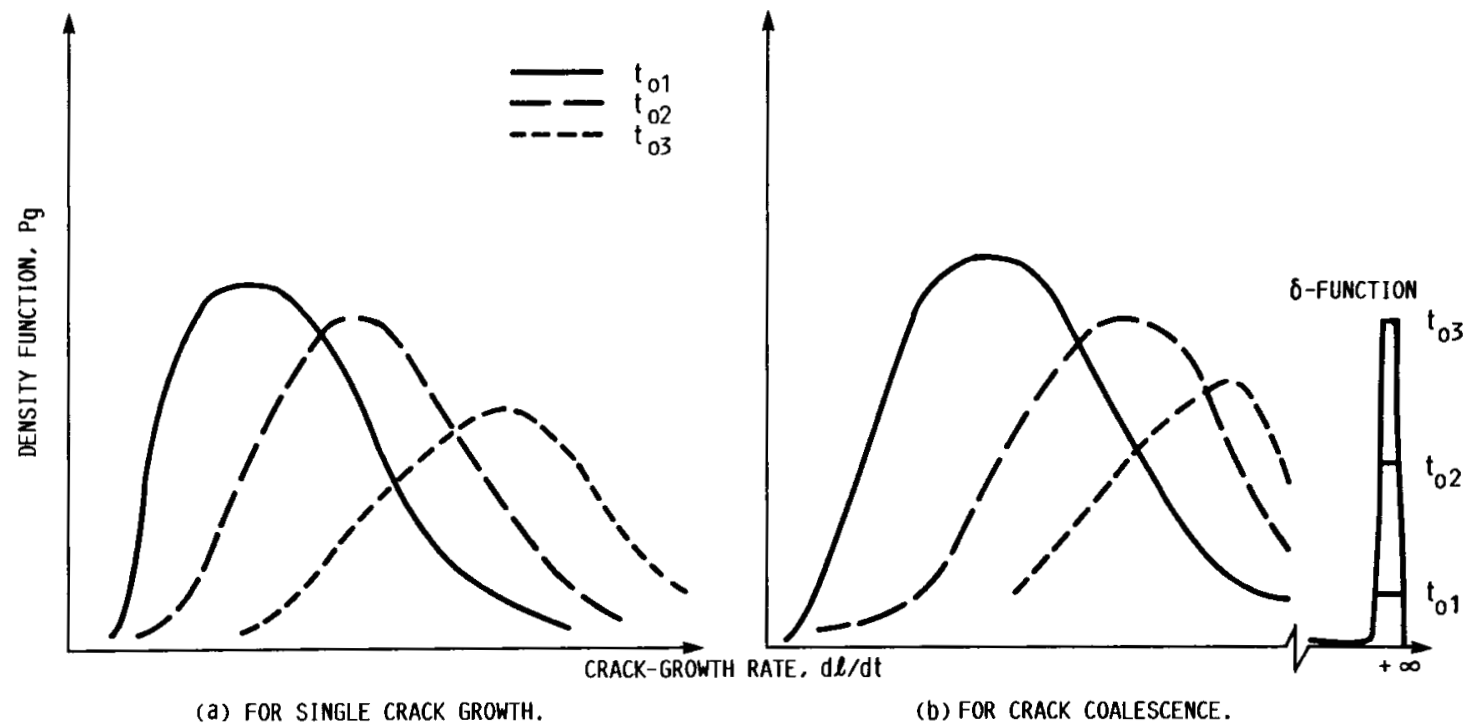

FIGURE 8. - DIAGRAM OF DENSITY FUNCTIONS OF CRACK-GROWTH RATE, GLOBAL STRESS, $\sigma_{g}$, CONSTANT; CRACK LENGTH, $\boldsymbol{l}$. CONSTANT; PREDAMAGE TIME. $t_{0} ; t_{01}<t_{02}<t_{03}$. 


\begin{tabular}{|c|c|c|c|c|c|}
\hline \multicolumn{6}{|c|}{ Report Documentation Page } \\
\hline & $\begin{array}{l}\text { Report No. } \\
\text { NASA TM-101358 }\end{array}$ & \multicolumn{2}{|c|}{ 2. Government Accession No. } & \multicolumn{2}{|c|}{ 3. Recipient's Catalog No. } \\
\hline \multirow{2}{*}{\multicolumn{4}{|c|}{$\begin{array}{l}\text { Stochastic Modeling of Crack Initiation and Short-Crack Growth Under } \\
\text { Creep and Creep-Fatigue Conditions }\end{array}$}} & \multicolumn{2}{|c|}{ January 1989} \\
\hline & & & & \multicolumn{2}{|c|}{ 6. Performing Organization Code } \\
\hline \multirow{2}{*}{\multicolumn{4}{|c|}{$\begin{array}{l}\text { 7. Author(s) } \\
\text { Takayuki Kitamura, Louis J. Ghosn, and Ryuichi Ohtani }\end{array}$}} & \multicolumn{2}{|c|}{$\begin{array}{l}\text { 8. Performing Organization Report No. } \\
\text { E-4388 }\end{array}$} \\
\hline & & & & \multicolumn{2}{|l|}{$\begin{array}{l}\text { 10. Work Unit No. } \\
505-63-1 B\end{array}$} \\
\hline \multirow{2}{*}{\multicolumn{4}{|c|}{$\begin{array}{l}\text { 9. Performing Organization Name and Address } \\
\text { National Aeronautics and Space Administration } \\
\text { Lewis Research Center } \\
\text { Cleveland, Ohio } 44135-3191\end{array}$}} & \multicolumn{2}{|c|}{ 11. Contract or Grant No. } \\
\hline & & & & \multicolumn{2}{|c|}{$\begin{array}{l}\text { 13. Type of Report and Period Covered } \\
\text { Technical Memorandum }\end{array}$} \\
\hline \multicolumn{4}{|c|}{$\begin{array}{l}\text { 12. Sponsoring Agency Name and Address } \\
\text { National Aeronautics and Space Administration } \\
\text { Washington, D.C. 20546-0001 }\end{array}$} & \multicolumn{2}{|c|}{ 14. Sponsoring Agency Code } \\
\hline \multicolumn{6}{|c|}{$\begin{array}{l}\text { Takayuki Kitamura, National Research Council-NASA Research Associate, on leave from the Department of } \\
\text { Engineering Science, Kyoto University, Kyoto, Japan; Louis J. Ghosn, Cleveland State University, Cleveland, } \\
\text { Ohio } 44115 \text {, and NASA Resident Research Associate; Ryuichi Ohtani, Kyoto University, Kyoto, Japan. }\end{array}$} \\
\hline \multicolumn{6}{|c|}{$\begin{array}{l}\text { A simplified stochastic model is proposed for crack initiation and short-crack growth under creep and creep- } \\
\text { fatigue conditions. Material inhomogeneity provides the random nature of crack initiation and early growth. In } \\
\text { the model, the influence of microstructure is introduced by the variability of (1) damage accumulation along grain } \\
\text { boundaries, (2) critical damage required for crack initiation or growth, and (3) the grain-boundary length. The } \\
\text { probabilities of crack initiation and growth are derived by using convolution integrals. The model is calibrated } \\
\text { and used to predict the crack density and crack-growth rate of short cracks of } 304 \text { stainless steel under creep and } \\
\text { creep-fatigue conditions. The mean-crack initiation lives are predicted to be within an average deviation of about } \\
10 \text { percent from the experimental results. The predicted cumulative distributions of crack-growth rate follow the } \\
\text { experimental data closely. The applicability of the simplified stochastic model is discussed and the future research } \\
\text { direction is outlined. }\end{array}$} \\
\hline & $\begin{array}{l}\text { Key Words (Suggested by Auth } \\
\text { Creep; Creep-fatigue; Cra } \\
\text { propagation; Stochastic mo } \\
304 \text { stainless steel; Grain-1 } \\
\text { Short cracks }\end{array}$ & $\begin{array}{l}\text { Crack } \\
\text { prediction; } \\
\text { cking; }\end{array}$ & $\begin{array}{l}\text { 18. Distribution } \\
\text { Unclass } \\
\text { Subject }\end{array}$ & $\begin{array}{l}\text { nent } \\
\text { - Unlimited } \\
\text { gory } 39\end{array}$ & \\
\hline & $\begin{array}{l}\text { Security Classif. (of this report) } \\
\text { Unclassified }\end{array}$ & 20. Security & $\begin{array}{l}\text { of this page) } \\
\text { lassified }\end{array}$ & $\begin{array}{c}\text { 21. No of pages } \\
20\end{array}$ & $\begin{array}{r}\text { 22. Price* } \\
\mathrm{A} 03\end{array}$ \\
\hline
\end{tabular}

